\title{
Suicide prevention strategies: Which one to consider?
}

\author{
S.M. Yasir Arafat ${ }^{1}$, Russell Kabir ${ }^{2}$
}

${ }^{1}$ Department of Psychiatry, Bangabandhu Sheikh Mujib Medical University, Dhaka, Bangladesh; \& Department of Public Health, ASA University Bangladesh. ${ }^{2}$ Senior Lecturer, Department for Allied and Public Health, Faculty of Medical Sciences, Anglia Ruskin University, Chelmsford, UK.

\section{Introduction}

Suicide is a preventable global public health problem but often neglected by policy makers and there lacks central suicide prevention strategy in many countries. ${ }^{1-3}$ Suicide kills nearly one million people globally and it is the one of the three leading causes of death. ${ }^{1}$ If the current trend continues it can kill 1.53 million people in 2020 stated by World Health Organization (WHO) ${ }^{-4}$ So, WHO focuses on suicide prevention and called on the countries to devise national suicide prevention strategies. ${ }^{1-4}$ Prevention strategies should be based on the risk factors and previous evidences revealed that past suicidal attempt is the most important predictor of future attempt as well as death by suicide. ${ }^{4}$ So, interventions to reduce the attempts and reattempts can be the focus of suicide prevention strategies. It was aimed to look into and sum up the suicide prevention strategies so that it can be considered as a base line for the countries yet to develop any national strategy.

\section{Means restrictions}

There is strong evidence that means restriction is associated with a decrease in suicide and can be a major strategy for suicide prevention. ${ }^{5-15}$ It is drawing more and more attention day by day. ${ }^{16}$ Means restriction is the restricting the availability of the lethal means of suicide. ${ }^{6,9,17}$ Strategies including restricting firearms by firearm legislation, ${ }^{6,16-19}$ restrictions of the availability as well as safer storage of the pesticides, ${ }^{6,7,17,18}$ using antisuicidal shower heads for hanging prevention, ${ }^{6}$ converting packaging of toxic analgesics into smaller ones, $6,18,19$ erecting the barriers in the jumping sites, ${ }^{6,16,19}$ gas detoxification, $6,7,16,17,19$ conscious prescription of barbiturates, ${ }^{6}$ restriction on charcoal buying ${ }^{6,19}$. At population level means restriction is a proved and effective strategy where the method is highly lethal ${ }^{7}$ though there is a concern of means substitution as people can switch to other methods of suicide. ${ }^{7,16,18,20}$ Means restriction can be seen as a continuum that can range from complete restriction of lethal methods to promotion of educational and social interventions. ${ }^{7}$

\section{Gatekeeper interventions}

Gatekeeper intervention is well proved evidence based strategy for suicide prevention. It includes a range of interventions focusing on community or organizational gate keepers those have contact with potentially vulnerable populations. . $^{811,13,14,21-26}$ It is an extreme opportunity to identify at risk individuals and report them to appropriate assessment and treatment. ${ }^{17}$ Gatekeepers include clergy, first responders, teachers, pharmacists, geriatric caregivers, journalist, police officers, personnel staff, and those employed in institutional settings, such as schools, prisons, military, coaches, peer helpers, youth workers, clinicians, co-workers, or other key stakeholders in the community who are in a natural position to carry out informal surveillance, detection, and assistance for those in need. ${ }^{6,17,25,27}$ Providing education to raise the awareness of risk factors, providing formal training to the gate keepers, changing in the policy to encourage help-seeking, making resources available are the key area in the gate keeper strategy. ${ }^{17,27}$ Systematic reviews revealed gatekeeper training is helpful in reducing the number of suicides. ${ }^{6}$

\section{School interventions}

Interventions at school for suicide prevention are well discussed and proven strategy based on the evidences. $^{8,10,11,14,17-19,23}$ School can be ideal place for mental health literacy, suicide risk awareness, skill trainings those have significant effects on suicide prevention. ${ }^{6}$ School based programs have proliferated as they have proven as cost effective and convenient way to reach the future generations. ${ }^{28}$ The goal of intervention is to raise the awareness regarding suicide in the students, train the students to recognize the possible signs of suicide and provide resources in the school as well as in the community regarding suicide. ${ }^{29}$ The programs mainly focus on reducing risk factors by early identification and reporting. Screening for mood disorders, substance abuse, suicidal ideations can act as a intervention and then training the school staff as gate keeper to increase the identification and reporting and finally input in the school curricula to raise awareness and to increase self-screening as well as referral regarding mental disorders and suicidality. ${ }^{19,28}$ Peer helper programs and postvention are two other interventions used in the school for the youths. ${ }^{19} \mathrm{~A}$ new school based prevention program is getting popularity named as Signs of Suicide (SOS) that incorporates the two interventions; combining the curricula to raise awareness and a brief screening for depression related issues in regards to the suicide. ${ }^{30,31}$ Yellow Ribbon program is another program used in some areas. $^{31}$

\section{Hotline interventions}

With rapid mobile using "Hotline" or emergency call can significantly delay the attempts and reduce the acute despair. Previous studies revealed that help

Correspondence: Dr. S.M. Yasir Arafat, Department of Psychiatry, Bangabandhu Sheikh Mujib Medical University, Dhaka, Bangladesh. Email: arafatdmc62@gmail.com. 
offered by telephone or well-known hotline number using reduce suicides significantly. ${ }^{9-11,14,22,32,33}$ Counseling services can be provided by both trained or untrained counselors in the community level and people in despair are encouraged to contact through a widely published number., ${ }^{5,14}$ Befriending approach is used in most of the hotline centres and unguided brief mobile intervention, telephone after care interventions delay and reduce suicide significantly. ${ }^{4-6,17,34,35}$ Moreover, totline services are approachable even in emergencies and can account earlier support than long waiting list. ${ }^{6}$ As well as reducing the suicidality the hotline interventions has a positive impact on the psychosocial aspects such as reduction of depressive symptoms, hospital admissions and health services resource utilization. $^{14}$

\section{Intervetions by primary care physicians}

As before the suicidal attempt, the contact with the primary care was found to be increased, and the role of primary care in suicide prevention was proved very important. ${ }^{8-11,13,14,36}$ Moreover, as depression is the most unrecognized and under treated; tolls a lion share in suicidality; addressing, screening, treatment and follow up of the depressed patients is a very important strategy to reduce suicide. ${ }^{17,37}$ Educating \& training the primary care physicians (PCP) regarding depression recognition and treatment is considered the most effective interventions for suicide prevention. $5,6,18,19,22,27$ Integrating the suicide prevention into the primary care and timely access to mental health care significantly reduces the depression as well as suicide. ${ }^{37}$ The primary care focused mental health care and general practice focusing on screening, detection, treatment, referral and follow up of the depression and other mental disorder can play as the most effective way of suicide prevention at community level. ${ }^{17,19,37}$ Telepsychiatric approach such as videoconfrencing, teleconferencing consulting methods can be used to support the primary care services. ${ }^{17}$ Recent evidences suggest the use of antidepressants in the primary care level to accelerate the suicide reduction. ${ }^{17}$ Few steps has been recommended in few articles such as enquiring regarding mood disorders, suicide and other risk factor, involving the family and other health care professionals, becoming familiar with the available resources to prevent suicide, self-education and educating the patients as well, close monitoring of depression, ensuring training for management of mood disorders. ${ }^{19}$

\section{Media and suicide prevention}

In this era of media, both electronic and print disseminate news in a blink and may affect the creation or alteration of suicide methods as well as overall suicidality. ${ }^{7}$ Insensible media reporting can affect suicides and mostly happens in cases of celebrity or iconic suicides. $5,7,1,10,13,14,23$ The phenomena is called as suicide contagion that is also referred to as imitative, copycat or mass cluster suicide. ${ }^{8,22,38}$ The effects of media on suicide found bidirectional as it is detrimental for the risky people but protective for someone who emphasize positive coping. ${ }^{6,7}$ Inappropriate media reporting of celebrity suicide was found to strongly associated with subsequent increase in suicidal behavior and vast studies suggest that the media coverage of suicide is associated with suicidality. ${ }^{38}$ Moreover, media black outs and better media reports reduces suicide as evidenced by previous articles. ${ }^{6}$ So, creating reporting guidelines and training the reporters, editors plays a vital role in suicide prevention. ${ }^{6,17}$ Past evidence consistently revealed that improvement of media portrayal of suicide, reduces the rate of suicide. ${ }^{18,38}$ and responsible media reporting is a recognized public health approach for suicide prevention. ${ }^{38}$ However, media can help in reducing suicide by raising awareness, ${ }^{38}$ reducing negative attitudes to mental disorders and suicide. ${ }^{22}$

\section{E-Health interventions}

E-health interventions are getting popularity in the globalized civilization. Different aspects can be utilized differently. Internet can be used to self-screening as well as to report to the psychiatric services providers that ultimately reduces the suicidality and further attempts. ${ }^{39}$ Both guided \& unguided web applications can be used to intervene the suicide. ${ }^{39,40}$ Another approach to indentify the risky people by assessing the social media contents such as status updates, posts, comments those are indicative of mental disorders or suicidal ideation. ${ }^{39,40}$ Web-based video and podcasting, outreach communications via e-mail, smartphones applications, computer and web-based gaming, text analysis and so forth strategy can be implemented to identify the risky person and to direct them to the services providers.

\section{Psychiatric morbidities and suicide}

Psychiatric morbidities are important risk factors for suicide. Repeated evidences suggest that about $90 \%$ of suicide victims had at least one mental disorder where depression was the main cause accounting about $60 \%$ of the deaths. $5,9,11,13,16,17,22,35,37$ Other psychiatric disorders found in psychological autopsies of suicidal deaths are personality disorders, ${ }^{16}$ adjustment disorder, ${ }^{35}$ alcohol and drug related disorders, ${ }^{11,16,17,35}$ bipolar disorders, ${ }^{22,35}$ schizophrenia and other psychotic disorder, ${ }^{16,35}$ anxiety disorders, ${ }^{35}$ impulse control disorders, ${ }^{35}$ somatoform disorders, ${ }^{35}$ sleep disorders, ${ }^{35}$ eating disorders, ${ }^{35}$ and childhood psychiatric disorders. ${ }^{35}$ Other risk factors can be accounted as availability of lethal means, psychiatric services availability, attitude to suicide, help seeking behaviors, comorbid physical illness and other social factors. ${ }^{17}$ Previous study revealed that up to $83 \%$ of committed suicides have had contacts with primary care physicians within a year and two third of them within a month. ${ }^{17,22}$ Treating mood disorders is a central approach of suicide prevention and primary care can be a very potential area for the same. Improved and regular screening of depressed patients with better treatment subsequently should be ensured in the primary care level. ${ }^{17,22}$ After ensuring acute management, long time follow up is also necessary as depression is chronic and recurrent disorder. ${ }^{17}$

\section{Pharmacological interventions}

As mental disorders toll a major part of suicide, hence treatment of the disorders with psychotropics is a remarkable part of suicidal prevention. ${ }^{14,18,22}$ Acute treatment can prevent suicide significantly as found in the previous researches as well as long term treatment of psychiatric disorders as prophylactic by antidepressants, mood stabilizers and antipsychotics substantially reduces the suicide attempts. ${ }^{22}$ Successful treatment of mood disorders can reduce the suicide in a 
given episode and prophylactic use of psychotropics can effectively reduce the suicidal attempt as well as mortality.

Lithium reduces the suicides of patients having affective disorders both unipolar depression and Bipolar disorders. ${ }^{5,6,11,13,17,22,41}$ The anti-suicidal as well as the mood stabilizing effects of Lithium relate more than other mood stabilizers. ${ }^{41}$ Lithium also has role in managing aggression and impulsivity that adds more benefit as aggression and impulsivity drag patients to suicide. ${ }^{13,41}$ Recent meta-analysis revealed that Lithium reduced the risk of completed and attempted suicide about $80 \%$ during treatment of major affective disorders. ${ }^{13}$ Clozapine (atypical antipsychotic) reduce suicidal attempts in the patients of psychosis and suicidal risk or attempt. ${ }^{5,6,11,13,17}$

Use of anti-depressants is very accountable strategy in suicide prevention as depression tolls a significant portion of suicide. Selective Serotonin Reuptake Inhibitor (SSRIs ) are the modern less toxic antidepressants which reduce suicides in depressive disorders in both short-term and long-term treatment. The drugs are considered as a first line therapy in primary care for major mood disorders. ${ }^{5,6,11,13}$ Though SSRIs may increase the suicidal thoughts initially but there is no support to increase the total suicides. ${ }^{6}$ However, 'sertraline is associated with decreased suicidal ideation and behaviour but not with emergent suicidal thinking or behavior' and adding cognitive behavioural therapy (CBT) to fluoxetine might reduce the suicidal ideation and behavior. ${ }^{6}$ Repeated studies revealed widely that reduction of suicides with increase sales of SSRIs. ${ }^{6,13}$

Electroconvulsive therapy (ECT) is an effective treatment for suicidality among severely depressed patients as evidenced by extensive literature and resistant depression with acute suicidal risk is a clear indication of ECT. ${ }^{6,13}$ Ketamin is also showed effectiveness and rapid reduction of suicidal thoughts in Ketamin medicated patients. ${ }^{6}$

\section{Psychological interventions}

Psychotherapy plays significant role in suicide prevention in reducing the acute emergency symptoms and long-term complications after proper correction of the cognitive distortions. ${ }^{8,28}$ For suicide prevention CBT, ${ }^{6,13,17,42}$ dialectical behavioural therapy (DBT), ${ }^{6,13}$ problem-solving therapy, ${ }^{6,13,17}$ a brief family-based crisis intervention and intensive care with outreach, ${ }^{6,17}$ interpersonal psychotherapy, ${ }^{13,17}$ were found effective. Study revealed that CBT reduces the suicidal attempt by halved in comparison with those with receiving usual care. ${ }^{17}$ In combination with anti-depressants psychotherapy can be effective treatment for depression, suicidal ideation, suicidal attempts in borderline personality disorder. ${ }^{13,17}$

\section{After discharge follow-up interventions}

Persons with mental disorders and suicidal risks or sever psychological crisis need urgent psychiatric admission for crisis management and psychotropics addition reduces the suicidality. ${ }^{11,22}$ Previous evidences revealed that suicidality is more in the early days of hospital discharge. So, long-term close observation as well as follow is recommended for reduction of further attempts. $^{13,22}$ Reduction of suicidal reattempts were found among the patients who were followed up with phone calls, post mails, emails than who were not followed up in such ways. ${ }^{4}$ Family member involvements, social programs have role in ensuring the long-term follow-up.

\section{Screening strategies}

Screening programs to identify risky individuals and then channeling them to treatment reduce suicide. $^{10,11,13,17}$ Regular screening for depression, suicidal ideation, suicidal acts, drug abuse, juvenile offenders among the youth can reduce suicide significantly as revealed in previous studies. ${ }^{10,11,13,17}$

\section{Conclusion}

Suicide is a preventable public health problem but many countries are yet to develop any national strategy. It was aimed to look into and sum up the suicide prevention strategies so that it can be considered as a baseline for the countries yet to develop any national strategy. The literatures revealed means restriction, gatekeeper strategy, school interventions, hotline services, educating the primary care physicians, sensible media reporting, e-health interventions and adequate psychiatric services are the effective suicide prevention strategies till date. No single strategy was found to universally superior. Focusing on the local risk and cultural diversity appropriate national suicide prevention strategy is a time demand without further delay.

\section{References}

1. Arafat SMY. Suicide in Bangladesh: a Mini Review. J Behav Heal. 2017;6(1):66-9.

2. Caine ED. Suicide Prevention is a Winnable Battle. Am J Public Health. 2012;102(S1):S16.

3. Manton A. Suicide prevention....Ask the question! JEmerg Nurs. 2016;42(6):467-8.

4. Ghanbari B, Malakouti SK, Nojomi M, Alavi K, Khaleghparast S. Suicide prevention and follow-up services: a narrative review. Glob $J$ Health Sci. 2016;8(5):145-53.

5. Rahim DAA. Fight against Suicide. J Enam Med Coll. 2015;5(1):4-5.

6. Zalsman G, Hawton K, Wasserman D, van Heeringen K, Arensman E, Sarchiapone M, et al. Suicide prevention strategies revisited: 10year systematic review. Lancet Psychiatry. 2016;3(7):646-59.

7. Yip PSF, Caine E, Yousuf S, Chang S Sen, Wu KCC, Chen YY. Means restriction for suicide prevention. Lancet. 2012;379(9834):2393-9.

8. Krysinska K, Batterham PJ, Tye M, Shand F, Calear AL, Cockayne N, et al. Best strategies for reducing the suicide rate in Australia. Aust New Zeal J Psychiatry. 2016;50(2):115-8.

9. Chiu HFK, Takahashi Y, Suh GH. Elderly suicide prevention in East Asia. Int J Geriatr Psychiatry. 2003;18(11):973-6. 
10. Gould MS, Kramer RA. Youth suicide prevention. Suicide Life-Threatening Behav. 2001;31 (Suppl):6-31.

11. Gould MS, Greenberg T, Velting DM, Shaffer D. Youth Suicide Risk and Preventive Interventions: A Review of the Past 10 Years. $J$ Am Acad Child Adolesc Psychiatry. 2003;42(4):386-405.

12. Wu KCC, Chen YY, Yip PSF. Suicide methods in Asia: Implications in suicide prevention. Int $J$ Environ Res Public Health. 2012;9(4):1135-58.

13. Schwartz-Lifshitz M, Zalsman G, Giner L, Oquendo MA. Can we really prevent suicide? Curr Psychiatry Rep. 2012;14(6):624-33.

14. Lapierre S, Erlangsen A, Waern M, de Leo D, Oyama H, Scocco P, et al. A systematic review of elderly suicide prevention programs. Crisis. 2011;32(2):88-98.

15. Betz ME, Miller M, Barber C, Miller I, Sullivan $\mathrm{AF}$, Camargo CA, et al. Lethal means restriction for suicide prevention: Beliefs and behaviors of emergency department providers. Depress Anxiety. 2013;30(10):1013-20.

16. Daigle MS. Suicide prevention through means restriction: Assessing the risk of substitution: A critical review and synthesis. Accid Anal Prev. 2005;37(4):625-32.

17. Mann J, Haas A, Mehlum L, Phillips M. Suicide Prevention Strategies. J Am Med A ssoc. 2005;294 (16):2064-74.

18. Bertolote JM. Suicide prevention: at what level does it work? World Psychiatry. 2004;3(3):14751.

19. Kutcher SP, Szumilas M. Youth suicide prevention. Can Med Assoc J. 2008 Nov 26;178 (3):282-5.

20. Florentine JB, Crane C. Suicide prevention by limiting access to methods: a review of theory and practice. Soc Sci Med. 2010;70(10):1626-32.

21. Knox KL, Litts DA, Talcott GW, Feig JC, Caine ED. Risk of suicide and related adverse outcomes after exposure to a suicide prevention programme in the US Air Force: cohort study. BMJ. 2003;327 (7428):1376-80.

22. Rihmer Z, Kantor Z, Rihmer A, Seregi K. Suicide Prevention Strategies - A Brief Review. Neuropsychopharmacol Hungarica. 2004;6 (4):195-9.

23. Cross WF, Seaburn D, Gibbs D, Schmeelk-Cone K, White AM, Caine ED. Does practice make perfect? A randomized control trial of behavioral rehearsal on suicide prevention gatekeeper skills. $J$ Prim Prev. 2011;32(3-4):195-211.

24. Wyman PA, Brown $\mathrm{CH}$, Inman $\mathrm{J}$, Cross $\mathrm{W}$, Schmeelk-Cone K, Guo J, et al. Randomized Trial of a Gatekeeper Program for Suicide Prevention: 1 -year Impact on Secondary School Staff. J Consult Clin Psychol. 2008;76(1):104-15.

25. Cross W, Matthieu MM, Lezine D, Knox KL. Does a brief suicide prevention gatekeeper training program enhance observed skills? Crisis. 2010;31(3):149-59.
26. Cross W, Matthieu MM, Cerel J, Knox KL. Proximate outcomes of gatekeeper training for suicide prevention in the workplace. Suicide Life Threat Behav. 2007;37(6):659-70.

27. Hegerl U. Prevention of suicidal behavior. Dialogues Clin Neurosci. 2016;18(2):18390.

28. Wyman PA, Brown $\mathrm{CH}$, LoMurray $\mathrm{M}$, Schmeelk-Cone K, Petrova M, Yu Q, et al. An outcome evaluation of the sources of strength suicide prevention program delivered by adolescent peer leaders in high schools. Am J Public Health. 2010;100 (9):1653-61.

29. Eckert TL, Miller DN, Dupaul GJ, Riley-Tillman TC. Acceptability of SchoolBased Programs. School Psych Rev. 2003;32 (1):57-76

30. Aseltine RH, DeMartino R. An Outcome Evaluation of the SOS Suicide Prevention Program. Am J Public Health. 2004;94 (3):446-51.

31. Wei Y, Kutcher S, LeBlanc JC. Hot idea or hot air: A systematic review of evidence for two widely marketed youth suicide prevention programs and recommendations for implementation. J Can Acad Child Adolesc Psychiatry. 2015;24(1):5-16.

32. King R, Nurcombe B, Bickman L, Hides L, Reid W. Telephone counselling for adolescent suicide prevention: changes in suicidality and mental state from beginning to end of a counselling session. Suicide Life Threat Behav. 2003;33(4):400-11.

33. Mishara BL, Houle J, Lavoie B. Comparison of the effects of four suicide prevention programs for family and friends of high-risk suicidal men who do not seek help themselves. Suicide Life Threat Behav. 2005;35(3):329-42.

34. Larsen ME, Nicholas J, Christensen H. A systematic assessment of smartphone tools for suicide prevention. PLoS One. 2016;11 (4).

35. Park S, Choi KH, Oh Y, Lee HK, Kweon YS, Lee CT, et al. Clinical characteristics of the suicide attempters who refused to participate in a suicide prevention case management program. J Korean Med Sci. 2015;30(10):1490-5.

36. Ramberg IL, Di Lucca MA, Hadlaczky G. The impact of knowledge of suicide prevention and work experience among clinical staff on attitudes towards working with suicidal patients and suicide prevention. Int J Environ Res Public Health. 2016;13(2).

37. Malakouti SK, Nojomi M, Poshtmashadi M, Hakim Shooshtari M, Mansouri Moghadam F, Rahimi-Movaghar A, et al. Integrating a suicide prevention program into the primary health care network: A field trial study in Iran. Biomed Res Int. 2015;2015:9. 
38. Sisask M, Värnik A. Media roles in suicide prevention: A systematic review. Int $J$ Environ Res Public Health. 2012;9(1):123-38.

39. Christensen H, Batterham PJ, O'Dea B. E-health interventions for suicide prevention. Int J Environ Res Public Health. 2014;11(8):8193-212.

40. Luxton DD, June JD, Kinn JT. Technology-Based Suicide Prevention: Current Applications and Future Directions. Telemed e-Health. 2011;17(1):50-4.
41. Bastiampillai T, Allison S, Gupta A, Chan SKW. Lithium, suicide prevention and unipolar depression? A ust N Z J Psychiatry. 2016;1.

42. Stanley B, Brown G, Brent DA, Wells K, Poling K, Curry J, et al. Cognitivebehavioral therapy for suicide prevention (CBT-SP): treatment model, feasibility, and acceptability. J Am Acad Child Adolesc Psychiatry. 2009;48(10):1005-13 